\title{
INVENTARIANDO A GRAFIA DA LUZ NAS DISSERTAÇÕES DE MESTRADO DO PROGRAMA DE PÓS-GRADUAÇÃO EM ANTROPOLOGIA SOCIAL/UFRGS ${ }^{1}$
}

Adriane Rodolpho;

Alfredo Barros

Cornelia Eckert

Édison Gastaldo

Liliane Guterres. ${ }^{2}$

\begin{abstract}
Equipe do Navisual, Laboratório de Antropologia Social, PPGAS/IFCH/UFRGS
\end{abstract}
\section{Introdução}

Em 1956, o antropólogo Marvin Harris de Columbia University, publicou Town and Country in Brazil, uma bela etnografia sobre uma cidade no interior do Estado da Bahia. Harris descreve a história da decadência de Minas Velhas, que nasceu da aventura pelo ouro no século XVIII, perdendo para outras vilas vizinhas, como Vila Nova, o estatuto de centro produtivo e aglutinador em torno de uma mercado econômico e centro cultural florescente.

Em 1959 o historiador Fernand Braudel, fascinado por explicar como se tece a vida dos homens no processo das mudanças temporais e históricas, as transformações sobrevindas as tradições, as efervescências e as reticências, as recusas, as cumplicidades e abandonos, reanalisa a obra de Harris em "Dans le Brasil Bahianais: le présent explique le passé". Criticando a fraca perspectiva comparativa, Braudel, entretanto, homenageia com esta releitura a obra de fôlego do antropólogo Harris, lastimando apenas a inexistência de qualquer ilustração, sobretudo a ausência total de fotografias, que sem dúvida, pondera ele, o livro mereceria conter.

Esta breve referência nos imerge no campo que gostaríamos de abordar, o da utilização da fotografia nos textos antropológicos. Os pêsames de Braudel à Harris apenas elucida o quanto a fotografia já era importante como fonte ilustrativa do contexto descrito desde os primeiros grandes antropólogos deste século. Bronislaw Malinowski, Evans-Pritchard, Gregory Bateson, Margaret Mead e tantos outros fizeram uso da fotografia em suas experiências etnográficas e na elaboração de uma antropologia descritiva aprofundada, como sugere Samain, em relação as fotografias e as legendas usadas por Malinowski (SAMAIN, 1995:27).

\footnotetext{
1 Uma versão preliminar deste texto será publicado em uma coletânea intitulada A Fotografia no Rio Grande do Sul, organizada por Luiz Eduardo R. Achutti e editada pela Prefeitura Municipal, sob o título "A Grafia da Luz na Narrativa Etnográfica".

${ }^{2}$ Agradecemos ao Prof. Dr. Mauro Koury pelas críticas e sugestões que muito contribuíram para a finalização deste texto.
} 
O uso que cada um destes antropólogos fez das imagens, entretanto, é completamente diverso, variando de acordo com "o que" cada um queria "mostrar" em suas fotografias. O próprio Lévi-Strauss excluiu da publicação de Tristes Trópicos as fotografias realizadas no trabalho de campo. Apenas quarenta anos depois, as imagens de uma das etnografias mais conhecidas do planeta nos são reveladas em Saudades do Brasil. ${ }^{3}$

O que de fato queremos destacar é a importância de conhecermos esta perspectiva histórica do uso da imagem na Antropologia. Esta reflexão tem promovido um novo campo de debate muito profícuo para os avanços epistemológicos da disciplina. ${ }^{4}$

O Núcleo de Antropologia Visual (NAVISUAL) ${ }^{5}$ tem como motivação de trabalho o ímpeto de perseguir a atualidade do uso da imagem na produção antropológica de cinema, vídeo e fotografia, promovendo o suporte visual como um instrumento eficaz de pesquisa. Neste sentido, este núcleo busca proporcionar um espaço de debate em torno da história da Antropologia Visual e da Imagem e a reunir pesquisadores que conjuguem o interesse em usar a fotografia e o vídeo como instrumentos de pesquisa e o conhecimento técnico e estético desses meios (seja em formação, seja adquirido).

Nesta oportunidade, nossa intenção é divulgar e avaliar as etnografias que fizeram uso do recurso fotográfico e que resultaram em dissertações de mestrado no Programa de PósGraduação em Antropologia Social (UFRGS) que informam sobre a experiência do NAVISUAL.

Analisando as dissertações produzidas nos anos 80 , pode-se sugerir que as fotografias sempre apareceram como importante dado etnográfico no procedimento de coleta e análise do material antropológico, quanto sempre tiveram destacado papel de ilustração do universo de estudo e de "situações de pesquisa visualmente prolixas"6 ou recorrendo para a descrição densa de forma imagética, convergindo no esforço do antropólogo de transcrever (traduzir) as interpretações dos aspectos temporais e contextuais da vida cotidiana, desvendando privilegiadamente os valores e códigos culturais que trazem à tona a problematização do

\footnotetext{
3LÉVI-STRAUSS, Claude. Saudades do Brasil. São Paulo: Companhia das Letras, 1994, p.228.

4 Vários Núcleos tem concentrado seus esforços neste projeto, a exemplo do Núcleo de Antropologia e Imagem - NAI que publica periódicamente os Cadernos de Antropologia e Imagem, Rio de Janeiro, UERJ.

5 Sobre as atividades do NAVISUAL veja o artigo ECKERT, C. et alii. "A experiência do Núcleo de Antropologia Visual UFRGS". In: ECKERT, C. e GODOLPHIN, N. (coord.). Revista Horizontes Antropológicos - Antropologia Visual. Porto Alegre: PPGAS-UFRGS n. 02, ano 1, 1995, p. 167-173.

6 Entrevista com Milton Gurhan In: ECKERT, C. e GODOLPHIN, N. (coord.). Revista Horizontes Antropológicos Antropologia Visual. Porto Alegre: PPGAS-UFRGS n. 02, ano 1, 1995, p. 159-166
} 
cotidiano, as relações sociais, as emoções e os conflitos, elucidando sobre o "o simbolismo inscrito na vida de todos os dias, no parentesco, na sexualidade, na política, etc"..7

De fato, o texto etnográfico tem por objetivo descrever uma experiência de investigação antropológica obtida pela observação direta e participante, e que explicita os instrumentos conceituais e teóricos através dos quais o antropólogo pesquisador objetiva sua análise científica.

Neste procedimento o estilo antropológico tende a adotar uma análise que desliza entre a explicação e a compreensão. Mas em ambas as tradições, o que se descreve são "fatos etnográficos", onde o próprio observador faz parte do processo de conhecimento e investigação como nos ensinaram os antropólogos modernos. A pesquisa etnográfica implica no estabelecimento de relações interpessoais, de diálogos, de trocas tanto quanto de evitações e hostilidades, experimentadas na situação de convivência com o grupo e sujeitos pesquisados. Em qualquer das tradições disciplinares certo é que o método antropológico se singulariza na maneira de vincular teoria e pesquisa de modo a favorecer novos procedimentos.

Observa-se, nesta última década, a crescente utilização do recurso fotográfico tanto na experiência de campo quanto no procedimento analítico e na construção do texto etnográfico, onde o NAVISUAL se destaca no apoio a novas experimentações e como um importante espaço de debate crítico.

Explicitamos nos próximos sub-ítens algumas reflexões em torno de questões técnicas relacionadas a obtenção dos registros fotográficos na investigação antropológica, seguido de um inventário da produção de monografias que fizeram uso deste recurso.

\section{A FOTOGRAFIA E A EXPERIÊNCIA DE CAMPO}

O método etnográfico é potencialmente qualificado para a utilização do instrumento fotográfico como recurso de obtenção de dados e, sobretudo, enquanto elemento de interação e trocas entre pesquisador e pesquisado. Estas experiências são bastante variadas em função das opções teóricas de cada pesquisador e da singularidade de cada processo de investigação.

O desenvolvimento da experiência de campo é também um tempo de crítica e relativização dos próprios pressupostos teóricos e conceituais do pesquisador, onde o recurso à fotografia pode igualmente proporcionar a produção de uma antropologia crítica que

\footnotetext{
7 BURKE, Peter. O mundo como teatro, estudos de antropologia histórica. Lisboa, Difel . p. 21.
} 
esclarece as diversidades destes usos. É também o momento onde o "olhar" antropológico vai exercitar-se, descobrindo seus limites e potencialidades.

Este exercício crítico revela a intencionalidade na fotografia etnográfica elucidando o fato de que ela não é, como ingenuamente se acreditava tempos atrás, um mero "espelho da realidade". Importa salientar os seguintes aspectos:

Em primeiro lugar trata-se de considerar o lugar do instrumento fotográfico no processo de construção do trabalho de campo. O pesquisador que opta por este instrumento não pode negligenciar a presença deste equipamento no processo de inter-relação. Neste sentido, o ato de fotografar pode inicialmente servir como uma importante estratégia de observação direta mas pode, sobretudo, permitir uma comunicação direta com o grupo pesquisado. É importante captar a tensão criada no jogo de reconhecimento entre o pesquisador e os sujeitos do universo pesquisado.

Em segundo lugar, na tarefa da coleta do material a fotografia é um instrumento coletor do dado bruto, que abrange o não descrito apenas pela palavra do pesquisador. Ela se transforma para este em um suporte de memória do fato etnográfico, propiciando assim uma análise posterior mais minuciosa do contexto e da disposição de certos elementos não verbais ou não verbalizáveis. O antropólogo Mauro Koury, ao analisar a primeira versão deste artigo, lembra que nesse sentido é importante não negligenciar o recorte ideológico do dado bruto, na medida em que coloca a memória no interior de um "suporte" do recorte registrado pelo observador.

Finalmente, salienta-se a importância da fotografia revelada como uma estratégia significativa de troca ou de "contradom" ao sujeitos entrevistados e/ou fotografados. Para, Godolphim (1995:130) a fotografia aparece:

"como elemento de interação na devolução do material fotográfico, estimulando a relação com o grupo estudado e abrindo um campo de diálogo, de expressão da memória e das reflexões dos informantes sobre as imagens devolvidas". (GODOLPHIM, 1995:130)

Este gesto de retornar para o informante a imagem captada, não o isenta do exercício crítico necessário sobre a imagem devolvida, sem perder de vista o quanto esta revela o olhar seletivo do pesquisador-fotógrafo sobre o contexto ou situação observados. A interação assim tem que ser apreendida também a partir desse recorte fotográfico feito pelo observador, sugere novamente Koury.

O procedimento de uma "vigilância epistemológica" é exercitado pelo pesquisadorfotógrafo ao longo de todo processo de obtenção, revelação e processamento da fotografia. De fato ao longo deste processo intervêm na prática antropológica e no uso dos instrumentos 
técnicos, as mais diversas instâncias de intencionalidade. Desde antes do momento da obtenção, na escolha de determinado equipamento, filme e iluminação, até a escolha de quais fotos serão efetivamente incorporadas ao texto etnográfico, quase tudo é arbítrio do antropólogo. Embora fixando a reflexão luminosa sobre objetos realmente existentes, a imagem fotográfica é tão sujeita a este arbítrio do pesquisador que pode-se denominá-la "imagem construída". Sugere-se que algumas destas instâncias, onde se manifesta a intencionalidade do etnógrafo, são:

$\mathrm{Na}$ escolha do filme a ser utilizado, o pesquisador-fotógrafo decide de antemão a natureza cromática das imagens a serem produzidas, se coloridas ou preto e branco. Fotografias preto e branco tendem a ressaltar os volumes, as formas e os contrastes das imagens, em termos de claro/escuro. Zonas de luz e de sombra tornam-se mais evidentes. Na fotografia colorida, a reprodução da ambiência é mais intensa, e objetos coloridos passam a ter uma importância enorme na cena, mesmo que distanciados do motivo. A sensibilidade da película utilizada também vai condicionar o resultado obtido. Um filme de ASA baixa vai requerer muito mais luz ambiente, ou forçar o fotógrafo a utilizar uma unidade de flash. De qualquer modo (caso esteja sendo utilizada uma câmara mono-reflex), para permitir uma velocidade suficiente para o manejo da câmara sem um tripé, o diafragma deverá estar muito aberto, resultando em uma zona de foco extremamente seletiva, o que também vai influir na enunciação final da fotografia. Com um filme rápido, haverá uma maior granulação, mas o pesquisador-fotógrafo poderá optar entre utilizar luz ambiente ou flash, ou ainda conseguir, com uma razoável velocidade, uma boa profundidade de campo para uma determinada cena, o que amplia as possibilidades enunciativas de suas obtenções.

Da mesma forma, a objetiva escolhida determinará em grande parte a ênfase da fotografia, mesmo antes de ser obtida. Uma objetiva grande-angular, pela sua amplitude de campo, abrangerá planos gerais da cena, causando distorção quando usada a curtas distâncias, enquanto uma teleobjetiva selecionará detalhes isolados, tanto pela pequena amplitude de campo quanto pela profundidade bastante restrita. Uma objetiva normal reproduzirá o campo de visão de um observador presente à cena, com um foco suficientemente seletivo para destacar zonas de particular interesse.

No momento da obtenção, já na pesquisa de campo, o pesquisador fotógrafo pode, a cada pose, destacar determinados elementos e esconder outros, selecionando as situações a serem registradas e descritas. Na medida em que a fotografia é sempre um recorte bidimensional sobre uma cena em três dimensões, reduzindo a um quadrado ou retângulo o que acontece em um determinado espaço, o posicionamento da câmara e sua regulagem para 
uma dada obtenção podem tornar a fotografia um ato de enunciação. Movendo a câmara para cima, para baixo ou para um dos lados, o pesquisador fotógrafo pode "incluir" um determinado ator ou cena na fotografia ou eliminá-lo. Variando a regulagem da velocidade, pode captar o movimento de um ator como um borrão ou congelá-lo em plena movimentação; com o anel do diafragma, pode situar a zona de foco em um único objeto ou em todos os objetos presentes no quadro.

Na seqüência do trabalho de obtenção, no processamento, o pesquisador fotógrafo tem mais uma oportunidade de "editar" o seu trabalho, caso realize pessoalmente o processo de ampliação de suas fotografias. Manipulando o ampliador, ele pode selecionar um determinado trecho de um negativo para ampliá-lo, ignorando o restante do fotograma, em mais uma instância de absoluta intencionalidade.

Após o processamento das cópias, cabe ainda assinalar a interferência do etnógrafo em suas fotografias no sentido de uma enunciação intencional, ao decidir quais fotografias serão escolhidas para integrar uma determinada descrição ou narrativa. É muito freqüente a obtenção de centenas de fotos de um determinado evento para tornar públicas apenas uma ou duas delas, que "dizem" exatamente a intenção do enunciador.

É evidente que para obter um relativo controle sobre o potencial enunciativo da fotografia é necessário uma certa experiência com o manejo do equipamento utilizado. Se a enunciação fotográfica pode ser considerada uma descrição etnográfica, deve-se aprender a técnica que lhe é inerente para um ato de comunicação preciso.

\section{A construção do texto e o lugar da fotografia}

As fotografias, ao serem conjugadas às etnografias, permitem que o fato etnográfico seja comunicado tanto pelo texto escrito quanto pela imagem. Associando ambos, reconhecemos o potencial da fotografia enquanto meio de comunicação contribuindo no relato etnográfico e análise teórica, permitindo ao leitor o conhecimento da pesquisa construída. Dessa forma, para além da intersecção do mundo do texto escrito com o mundo do leitor, a fusão desses horizontes pode ser motivada pela imagem produzida.

A imagem e a descrição etnográfica abarcam estilos diferentes, tradições diversas, mas passíveis de serem associadas. A primeira aciona percepções para além daquelas permitidas pela escrita, alcançando uma forma singular de transmissão do conhecimento que ultrapassa os limites deste campo. Na intersecção destes campos a narrativa etnográfica pode ser construída a partir do suporte da imagem, como força estilística de descrição do contexto vivido e processo de pesquisa. Sugere-se um ganho no recurso comunicativo que aproxima o 
pesquisador, os atores ou sujeitos pesquisados e os leitores do processo de conhecimento construído.

Não existe um modelo fechado sobre o uso da fotografia nas produções acadêmicas, antes pode-se sugerir, que este tem sido um espaço extremamente criativo e inovador. Mas a motivação para o seu uso, reflete com certeza um estímulo da instituição como de alguns Programas de Pós-Graduação em Antropologia abrigando Núcleos e Laboratórios voltados para a pesquisa com imagem. Com este estímulo, pesquisadores tem recorrido cada vez mais ao instrumento visual em suas investigações, o que lhes exige uma abertura interdisciplinar constante buscando aprender e dialogar com o campos das técnicas fotográficas, das artes, da história, da semiótica, das tecnologias, etc.

A análise do uso da fotografia exige, sem dúvida, uma incessante reflexão sobre esta teoria em ato, sobre os campos teóricos e conceituais propostos pelo pesquisador, suas intencionalidades metodológicas e instrumentais. Neste leque de démarches a serem analisadas, nosso fôlego é limitado a revisitar as diversas experiências do uso da fotografia nas dissertações de mestrado do PPGAS, colocando em alto relevo suas perspectivas ilustrativas, descritivas e narrativas. Um outro aspecto a considerar, e não menos relevante, é nos darmos conta da evolução da informática neste pequeno percurso aqui analisado. Trata-se aqui das potencialidades de diagramação do texto e de conjugação texto-foto que o desenvolvimento da tecnologia informatizada proporciona. Desta forma, são possibilitadas novas apresentações (diagramação da página), estilos alternativos, enfim todo um campo de novas experimentações na apresentação e reprodução da imagem, solucionando sobretudo o grande problema da perda de nitidez no processo de fotocópia das fotos originais. Os limites técnicos são cada vez mais superados devido a forma acelerada com que são popularizados os recursos tecnológicos no campo da informática.

Dessa forma, realizamos uma breve descrição das produções do PPGAS a fim de inventariar sobre estas diferentes formas do tratamento da imagem nas dissertações.

Num total de 65 teses defendidas até 1997, 20 antropólogos usam a fotografia nos seus trabalhos etnográficos:

A primeira dissertação defendida, no ano de 1983, foi a de Ondina Fachel Leal intitulada A leitura social da novela das oito. Na ocasião a autora já fez uso de 15 fotografias P\&B tamanho 22x14, impressas em off-set inserindo uma foto por página, reunindo-as em um único Capítulo. A autora discute o uso das fotos no Capítulo VI, onde esclarece:

"optei por um texto fotográfico que recomponha com outra grafia a descrição dos universos onde a novela é captada (...) [as fotos] omitem legendas, porque acredito que faça 
Esta dissertação sobre recepção televisiva foi posteriormente (1986) publicada em forma de livro com o mesmo título. Desta vez as fotos aparecem no Capítulo 1 "Descobrindo o objeto: a novela das oito" onde a autora sobrepõe o seu estudo sobre as imagens da televisão, com as imagens das pessoas a respeito daquelas imagens e das imagens da própria autora sobre estes imaginários. A autora relaciona aqui o seu objeto de estudo - seqüência de imagens - com o seu próprio aprendizado de fotografia. Como esclarece:

\footnotetext{
"não estou me referindo apenas à parte do trabalho em que a fotografia entra como dado. Refirome à pesquisa como um todo, desde sua formulação. A minha prática de pesquisa está comprometida com a prática de fotografar, mesmo quando estou sem a câmara". (LEAL. 1986:15,16)
}

O privilégio dado pela autora ao recurso da fotografia abre caminho para o uso deste instrumento ligado a uma reflexão epistemológica na investigação antropológica no âmbito do Programa de Pós-Graduação em Antropologia Social (UFRGS). Como diz a autora:

\begin{abstract}
"A fotografia é um aprendizado de observação paciente, de elaboração minuciosa de diferentes estratégias de aproximação com o objeto, de desenvolvimento de uma percepção seletiva, de uma vigilância constante e de prontidão para captar o acontecimento no momento do acontecimento. A dupla capacidade da câmara de subjetivar e objetivar a realidade, a constante consciência de que se é o responsável por este processo, por uma técnica de apreensão da realidade, de que se é sujeito deste conhecimento, é um ensinamento epistemológico. (...) $O$ ato de fotografar nos traz uma noção de posse de realidade e, ao mesmo tempo, a certeza da impossibilidade desta posse, de sua fragmentação, e necessidade de reconstrução e processo de revelação desta realidade. A nossa relação com o objeto é sempre uma relação de conhecimento e de poder onde um capta e o outro é captado. Fotografar é um cultivo didático do prazer da percepção do detalhe e do todo, que passa ou não pela técnica da objetiva, da grande-angular, do enfocar e desenfocar, dos diferentes tons possíveis na impressão e, enfim, da revelação da imagem - que não é mais a coisa fotografada (mas sempre plena de vestígios do real): a realidade revelada. Na fotografia, como no processo de conhecimento, e insisto no paralelo, a realidade só se torna objeto como coisa pensada". (LEAL. 1986:16).
\end{abstract}

"Boas para pensar" as 15 fotografias de interiores das unidades domésticas pesquisadas são apresentadas por Leal numa seqüência no subcapítulo "Os televisores, os objetos, os gostos e seus espaços", motivando o questionamento sobre o lugar dos aparelhos televisores 
nas unidades domésticas a partir de uma etnografia dos objetos e dos próprios espaços dos objetos (LEAL 1986).

No ano seguinte, outra dissertação é defendida fazendo o uso da fotografia. Tendo por tema "Bailões, é disto que o povo gosta: Análise de uma prática cultural de classes populares no Rio Grande do Sul', Maria Eunice de Souza Maciel inclui sete fotografias fotocopiadas em anexo, salientando em legenda que as mesmas são de autoria do senhor Omar Júnior, fotógrafo do "Bailão do Cardoso", universo dos exercícios de observação participante da antropóloga. (MACIEL, 1984).

Em 1985, a antropóloga Cornelia Eckert apresenta em sua dissertação, Os Homens da Mina: Um Estudo das Condições de Vida e Representações dos Mineiros de Carvão em Charqueadas - RS, 54 fotos realizadas pela autora e 15 de época cedidas pelos informantes, com aspectos cromáticos (P\&B/Cor) e tamanhos variados. Com o objetivo de ilustrar o contexto pesquisado, encontramos em geral as fotos em seqüências temáticas nas páginas finais de cada Capítulo, assim como anexadas no final da dissertação. A autora recorre a legendas para esclarecer as especificidades de cada foto.

Carmen Silvia Rial apresenta sua dissertação de mestrado em 1988 sob o título $O$ Mar de Dentro: a transformação do Espaço Social na Lagoa da Conceição, constando de 37 fotografias e dois cartões postais. Conjugadas ao texto escrito, as fotos aparecem em fotocópia preto e branco e em fotocópia verde, sendo a maioria nas dimensões 10 x 15 . No segundo capítulo intitulado "Metodologia", a autora assinala:

"A fotografia e os esboços das plantas baixas das casas foram importantes no registro e interpretação para a apreensão dos esquemas básicos das casas, dos arranjos internos e da decoração". (RIAL 1988:28).

Rial insere a maior parte das fotos entre parágrafos, optando por formas diversas de disposição das fotografias no texto. Na maioria das vezes, apresenta duas fotos ocupando por inteiro uma página. Outro estilo é uma foto ocupando meia página seguida de texto, ou ainda parágrafo-foto-parágrafo. Significativo também é o estilo adotado pela autora que consiste em realizar seqüências fotográficas que variam de 4 até 13 imagens sobre um mesmo tema. (Exemplo: informantes processando a farinha de mandioca nos engenhos catarinenses). Nestas sequiências, Rial recorre também a reproduções de fotos de época. Todas as fotos são legendadas mas não numeradas e o trabalho apresenta índice de ilustrações onde são identificadas as fotografias de forma mais ampla possível, não reproduzindo-se a legenda (Exemplo: Fotos: Estrada; Fotos de Engenho; Foto Cozinha Nova, etc). 
A partir da década de 90, até o presente momento, inventariamos quinze dissertações do PPGAS que fizeram uso do recurso imagético. Em 1991, Celso Dias apresenta em Olê, Olá, Nosso Time Tá Botando Prá Quebrá: um estudo sobre torcidas organizadas de futebol no Brasil, treze fotografias coloridas tamanho $10 \times 15$. Insere todas as fotos no segundo capítulo. O autor não discute a inserção de fotografias no trabalho, no entanto, na última página da introdução refere-se sucintamente às imagens utilizadas, desenhos e fotografias:

"para auxiliar à localização das principais regiões do estádio que se relaciona com as atividades das torcidas organizadas" (DIAS, 1991: 27).

As fotografias, em papel brilhante, foram coladas diretamente sobre a folha ocupando desta forma cerca de metade da página. Todas as fotos estão acompanhadas de legenda onde o autor as enumera e as descreve sucintamente (Exemplo: Foto 1: Visão privilegiada dos integrantes das torcidas organizadas). Apresenta uma fotografia por página, sem fazer uso de moldura.$^{8}$

Em 1993 Jurema Gorski Brites apresenta seis fotografias coloridas tamanho 12 x 18 em sua dissertação de mestrado Aprendiz de Bacana: Mobilidade Social e Sociabilidade em uma Terreira Afro-Brasileira. As fotos não estão propriamente inseridas no texto mas entre páginas: no Capítulo 3 quatro fotos e no Capítulo 4, duas fotos. São apresentadas duas fotos por página em fotocópia colorida, dispostas horizontalmente e sem uso de moldura ou legendas.

Uma outra dissertação neste período que inclui fotografias é a de Josiane A. Silva, intitulada Bambas da Orgia, um estudo sobre o carnaval de rua de Porto Alegre, seus carnavalescos e os territórios negros de 1993. A autora usa diversas imagens de mapas no texto, em um total de oito fotografias coloridas coladas diretamente na página. Opta por inseri-las no texto, uma por página, sem uso de molduras e numeração e com legendas.

Em 1994, o instrumento fotográfico foi utilizado em quatro novas dissertações de mestrado.

Adriane de Mello Boff, em O Namoro Está no Ar... Na Onda do Outro: Um Olhar Sobre os Afetos em Grupos Populares, apresenta 56 fotografias coloridas digitalizadas em $\mathrm{P} \& \mathrm{~B}$, de tamanho variável, de $8 \times 14$ ou 4,5 x 7. A autora insere as fotos nos capítulos assim dispostas: trinta e oito estão no Capítulo I (Introdução), treze no Capítulo II, três no Capítulo III e duas no Capítulo IV, sendo que os Capítulos V e VI não apresentam fotos. Algumas vezes as fotos aparecem numa seqüência que pode chegar a seis páginas só de imagens com

8 A moldura, este retângulo que envolve a imagem, é denominado no meio jornalístico de "fio". 
legendas temáticas, mas esta forma de apresentação recebe outras variações. Em outros momentos, a autora diagrama a página inserindo de 1 a 4 fotos, seguido de texto, não fazendo uso de moldura nas fotografias. As fotos ora são introduzidas por uma legenda temática, ora a foto é acompanhada de uma legenda explicativa. Não estão numeradas.

Em seguimento, Cláudia Turra Magni defende a pesquisa Nomadismo Urbano: Uma Etnografia Sobre Moradores de Rua em Porto Alegre. Num total de 117 fotos digitalizadas, a autora ainda inclui uma foto de época, cinco mapas e um anexo com trinta e nove desenhos. Todas as fotografias estão numeradas e legendadas, sendo que o tamanho das mesmas é bastante variado. A autora rompe com a sequiência tradicional texto-foto-texto, diagramando as páginas de forma diversa, ora expondo uma seqüência de fotos com uma mesma temática, ora inserindo a foto ao lado do parágrafo ou mesmo dispondo, numa mesma página, fotos de tamanhos diferentes. No Capítulo II encontram-se treze fotos, no Capítulo III vinte e nove fotos, no Capítulo IV quarenta e oito e no Capítulo V, vinte e seis fotos. Para a autora, o dado fotográfico não atua apenas como complementar ou subsidiário à pesquisa, mas "representou a chance de analisar e refletir através da natureza mais perene do registro, esta realidade fugidia - nômade, tal qual os sujeitos que a constróem" (MAGNI, 1994: 14-15).

Tendo por tema o universo batuqueiro porto-alegrense, Jacqueline Britto Pólvora inclui na sua dissertação A Sagração do Cotidiano: Estudo de Sociabilidade de um Grupo de Batuqueiros - Porto Alegre/RS uma discussão sobre a utilização da máquina fotográfica no trabalho de campo (PÓLVORA, 1994:27) . Quanto à inserção de fotos no trabalho, assinala:

\footnotetext{
"As fotos que veremos, inserem-se no texto como uma forma de ampliar e diversificar a escritura, trazendo ao leitor informações visuais impossíveis de serem registradas fidedignamente no diário de campo. Elas revelam imageticamente a ambiência, as formas e cores que são descritas ao longo do trabalho" (PÓLVORA, 1994:31).
}

São 90 fotografias coloridas de tamanho 7,5 x 11 e $6,5 \times 9,5$. A autora insere todas as fotos no meio do texto. Uma foto na epígrafe, onze no Capítulo 1; onze no Capítulo 2, quinze no Capítulo 3 e 52 no Capítulo 4. No final da introdução (pág. 32) avisa que todas as fotos, com exceção de uma, são de sua própria autoria. As fotos originalmente coloridas foram fotocopiadas em cores e em tamanho reduzido e posteriormente coladas na folha. Apresenta uma foto por página, algumas vezes duas. Não há legendas ou numeração e todas as fotos foram emolduradas.

Adriane Luisa Rodolpho, em 1994 apresenta Entre a Hóstia e o Almoço: Um Estudo Sobre o Sacrifício na Quimbanda, constando de 39 fotografias coloridas tamanho 9 x 6,5 fotocopiadas em cor e coladas na folha. A autora insere todas as fotos no meio do texto. Duas 
fotos na epígrafe, doze no Capítulo 1, vinte e quatro no Capítulo 3 e uma no Capítulo 4. Geralmente é apresentada uma foto por página, entre parágrafos; entretanto aparecem também duas por página. Utiliza moldura mas não há legendas ou numeração de fotos.

Já em 1995, Édison Gastaldo, defende a dissertação Kickboxers: Esportes de Combate e Identidade Masculina. Sendo publicitário e fotógrafo de formação, Gastaldo discute o uso das fotos no seu trabalho e o papel da fotografia no processo de retorno das mesmas aos informantes que as comentavam e interpretavam. Explica o autor:

\footnotetext{
“(...) foi realizada uma extensa cobertura fotográfica de treinos, lutas de demonstração e combates oficiais. Estas fotografias foram utilizadas não só como material etnográfico, como uma forma auxiliar na descrição de locais e eventos, mas também foram posteriormente mostradas aos praticantes, sendo seus comentários a respeito anotados, fornecendo novos dados acerca do grupo pesquisado, além de estabelecer uma espécie de troca, que levou a um ganho em sociabilidade e confiança por parte do grupo. Parte destas fotografias encontra-se no corpo deste trabalho."(GASTALDO, 1995: 9).
}

São ao todo 22 fotografias. O tamanho é variável e a digitalização das fotos interferiu no seu tamanho original. São apresentadas em 10 x 14; 14,5 x 12,5; 14 x 12; 14,5 x 9,5; 10 x 15; $14,5 \times 11$, etc. As fotografias foram incorporadas no meio do texto e apresentadas uma por página. Todas as fotos são legendadas e numeradas (Exemplo: Foto 1: Poster de Bruce Lee, Academia Central), mas não estão emolduradas.

Abrindo a Introdução, o autor apresenta uma foto que mostra dois homens em combate, seguida de uma epígrafe sendo que esta foto foi editada digitalmente, de forma que se vê apenas o contorno dos corpos em luta. As demais fotos estão inseridas no meio do texto, na forma que se segue: duas fotos no Capítulo 1; dez no Capítulo 2, oito no Capítulo 3 e uma foto no Capítulo 4.

As fotos originais, captadas em cor, foram digitalizadas e apresentadas na dissertação em P\&B. As fotos coloridas puderam, entretanto, ser apreciadas em diversas exposições fotográficas organizadas pelo NAVISUAL.

Cabe aqui ressaltar um problema técnico freqüente com relação as fotografias captadas em cor no processo da pesquisa. Geralmente estas fotos são reproduzidas em P\&B nas cópias das dissertações a que o grande público tem acesso. Isto significa que o retorno oferecido ao grande público contém apenas fotocópias monocromáticas de fotos que apresentam uma perda de qualidade técnica e estética considerável se comparadas com suas originais coloridas. Retomaremos esta problemática nas considerações finais. 
No mesmo ano Iosvaldir Bittencourt Júnior apresenta em Relógios da Noite, uma Antropologia da Territorialidade e da Identidade Negra em Porto Alegre 14 fotografias fotocopiadas coloridas, todas 10 x 15. As fotos estão em Anexo (Anexo A, B, N, O... ), sendo uma foto por página, centralizada. Não utiliza moldura e não há numeração de fotos, mas todas estão legendadas, sendo que a primeira palavra da legenda está com letras maiúsculas, chamando a atenção do leitor para um aspecto específico. (Exemplo: ESQUINAS: os pontos de encontro transicionais, mantidos pelos negros, são constituídos pelas esquinas, ruas, bares e galerias comerciais na área central da cidade).

Ainda em 1995 Maria Letícia Mazzucchi Ferreira abordando o tema da velhice, defende o trabalho Folheando o Passado: Um Estudo Antropológico Sobre Memória e Identidade Social na Velhice. Na página 175 a autora esclarece que, por não dominar o manejo da máquina, optou por convidar uma fotógrafa profissional para realizar as fotos na pesquisa de campo. Segundo a autora:

\begin{abstract}
"A imagem foi analisada através de dois procedimentos metodológicos distintos. Em um deles, o material de análise foram as imagens fotográficas já existentes nos espaços, tais como as fotos familiares (...) o outro procedimento consistiu em produzir fotografias de algumas idosas, buscando através da leitura posterior feita sobre a imagem fixada, os elementos recortados por elas que ajudam a estabelecer essa imagem de si mesma no presente". (FERREIRA, 1995: 175)
\end{abstract}

Ao mesmo tempo a autora discute a imagem fotográfica como tendo um estatuto próprio. Sugere que a imagem é um produto de subjetividades, tanto do fotografado como de quem aciona o mecanismo, e, num terceiro momento, se manifesta como o olhar diferenciado sobre o mesmo objeto, "a imagem perenizada” (FERREIRA. 1985:10). No último capítulo da referida dissertação, intitulado "Com os olhos fixos na eternidade: Fotografia e recordação", a autora analisa "as relações que esses sujeitos estabelecem com a imagem fotográfica". (FERREIRA. 1985 id.)

A capa da dissertação é ilustrada com uma foto de época, e as demais fotos, num total de nove fotografias coloridas de tamanho variado, entre $11,5 \times 16,5$ e 12 x 17,5 estão todas incluídas em anexo. As fotos foram fotocopiadas em cor, sendo uma foto por página, todas com legendas, não numeradas, nem emolduradas.

Também João Aníbal dos Santos, em 1995, incorpora na sua dissertação de mestrado Televisão: Cultura Local e Cultura de Massa Global. Etnografia da Audiência Entre Descendentes de Imigrantes Alemães seis fotografias coloridas tamanho 12 x 9. Estas são inseridas no início do trabalho em duas folhas separadas, cada uma contendo uma fotografia 
acompanhada de uma poesia. As demais fotos aparecem em anexo num total de duas páginas com duas fotografias cada (Anexo 1a, 1b, 1c, 1d). Reproduzidas em papel colorido e coladas sobre a página, o autor não faz uso de legendas ou molduras.

Em 1996 Liliane Stanisçuaski Guterres apresenta "Sou Imperador até morrer", um estudo sobre identidade, tempo e sociabilidade em uma Escola de Samba de Porto Alegre fazendo uso de 131 fotografias coloridas fotocopiadas em tamanho 7,5 x 5. Na introdução a autora discute questões como a relação do grupo estudado com a máquina fotográfica e sobre a experiência de devolução das fotografias para os informantes. Em continuidade, problematiza de forma inovadora o trabalho de inserção das fotos na dissertação, o processo de seleção das mesmas, a importância da documentação audio-visual, a discussão sobre Antropologia Visual e a questão da técnica fotográfica. Diz Guterres:

\begin{abstract}
"A máquina fotográfica acompanhou-me durante toda a pesquisa, o que permitiu a construção de um acervo fotográfico de cerca de duas mil e quinhentas fotos, todas coloridas. Sobre este acervo foram feitas inúmeras seleções buscando recortar o amplo material visual e conformá-lo em uma mostra que, originalmente, previa entre 60 a 80 fotografias a serem inseridas neste trabalho dissertativo. Este material, portanto, foi sendo gradativamente recortado até assumir a forma em que agora é exposto. Algumas fotos, de antemão cortadas, não-selecionadas para compor o trabalho devido a problemas técnicos (pouca ou muita luz, desfocadas), acompanharam todo o processo de escrita da dissertação indicando sua vital contribuição enquanto instrumento de compreensão do objeto de estudo. Entretanto, embora sua significação extrapolasse a barreira estética, optamos por buscar selecionar fotos não só boas de serem "lidas" mas também para serem "vistas". (GUTERRES, 1996:14).
\end{abstract}

A dissertação tem na sua abertura uma foto ampliada 41 x 29 , na capa interna, em fotocópia. A grande maioria das fotos desenvolvidas pela autora, estão inseridas e incorporadas ao texto da seguinte forma: uma foto na Introdução, 29 fotos no Capítulo 3, 84 fotos no Capítulo 4 e 15 fotos no Capítulo 5. Acrescenta uma reprodução de foto antiga no Capítulo 2 e quatro fotos de autoria dos bolsistas do NAVISUAL, cujos nomes aparecem assinalados com letra pequena na vertical da própria foto. A autora não faz uso de legenda ou numeração e todas as fotos estão emolduradas. Muitas páginas apresentam uma única ou duas fotografias, mas é recorrente o uso de sequiências de 3 ou 4 fotos por página.

Também em 1996, Implantando o Estatuto: Um Estudo Sobre a Criação de um Sistema Próximo ao Familiar para Crianças Institucionalizadas na FEBEM/RS, de Andrea Daniella Lamas Cardarello faz uso de 16 fotografias 10 x 15, todas colocadas em Anexo. Após a legenda a pesquisadora identifica a autoria das fotos, sendo que quatro delas são da própria, 
duas da monitora Marta Verran e as restantes de Luiz Eduardo Achutti. São diagramadas duas fotos por página e algumas estão colocadas horizontalmente. A autora não faz uso de moldura nas fotografias, todas aparecem legendadas e numeradas.

Ainda em 1996, Elena Salvatori analisa o espaço urbano de prestígio, a sociabilidade e estilo de vida em Nem Tudo Que Reluz É Ouro. Estilo de Vida e Sociabilidade na Construção de um Espaço Urbano de Prestígio em Porto Alegre/RS. A autora utiliza quarenta fotografias coloridas tamanho 10x15, apresentadas em volume separado. Neste volume um índice das ilustrações indica a organização temática das fotos (exemplo: Anexo 3 - Ilustrações ao Capítulo V, ítem 2 "ambientes urbanos e estilos de vida"), dispostas da seguinte forma: duas por página, todas com legendas e numeradas. As fotos foram agrupadas em tópicos (3.1, $3.1 .1 ; 3.1 .2$, etc) e apresentadas sem moldura.

Graduado em Ciências Sociais e fotógrafo profissional, Luiz Eduardo Robinson Achutti, em 1996, defende a primeira dissertação com temática eminentemente de antropologia visual. Intitulada Fotoetnografia: Um Estudo de Antropologia Visual Sobre Cotidiano, Lixo e Trabalho em Uma Vila Popular na Cidade de Porto Alegre. A pesquisa de Achutti é desenvolvida na Vila Dique, tratando da estética de grupos populares. O autor explica que seu trabalho é composto de duas partes, uma teórica e outra prática. De acordo com Achutti:

\footnotetext{
"Na primeira busco inventariar obras teóricas sobre a fotografia, a antropologia e as articulações entre ambas no que se usou chamar de uma antropologia visual. A segunda parte do trabalho é um exercício de antropologia visual realizado na Vila Dique, favela na periferia da cidade de Porto Alegre - RS. (...). Procurei, teoricamente, trabalhar a questão da imagem em seu potencial descritivo e suas históricas conexões com a antropologia. Meu objetivo foi descrever, através da fotografia, a qual chamo de fotoetnografia, a estética, de uma perspectiva de cultura popular, e a identidade deste grupo (...)".(ACHUTTI,1996: resumo)
}

No primeiro capítulo trata da "HISTÓRIA - Fotografia e Etnografia" onde analisa as conexões entre fotografia e etnografia, a fotografia e o método de pesquisa antropológica no século XX, a fotografia jornalística, "documentary photography", a antropologia visual e a chamada fotoetnografia. No segundo capítulo analisa a dinâmica e a diversidade do olhar, o surgimento da imagem fotográfica e o surgimento da imagem virtual. O terceiro capítulo trata da fotografia através dos aspectos mediação, técnica e narração, analisa a questão da estética e da mensagem, a fotografia como narrativa etnográfica, a virtualidade e multimídia. No 
capítulo 4 apresenta o que chama de fotoetnografia da Vila Dique, capítulo estruturado unicamente através de fotografias baseado nesta sua experiência etnográfica.

O autor apresenta um total de 101 fotografias coloridas e digitalizadas, de tamanho variável $(15 \times 22,5 ; 15$ x 10;8,5 x 6,0 e 6,5 x 4) e as insere todas no capítulo VI, dividido em 6 seções. Na abertura do trabalho o autor apresenta uma foto 10,5 x 16. Na primeira seção "A vila" apresenta 24 fotos, na maioria das vezes uma por página. Em alguns casos, há seqüências de fotos numa mesma página. Na seção dois "O trabalho e o lixo" constam 30 fotografias, na seção três "Retratos da Vila", 13, na seção quatro "As Casas", 9 fotos, na seção cinco, 15 e, finalmente, na seção seis, 10 fotografias. Como inovação, o autor coloca em anexo o que chama de "Mosaicos" onde reúne em cada página a sequiência das fotos apresentadas em cada seção, no formato de contatos $2,5 \times 1,7$. Todas as fotos estão emolduradas e sem legenda.

Em 1997, Maria Helena Sant'Anna defende a dissertação Vila Cai-Cai: A Lógica da Habitação Reciclável. Estudo da Organização do Espaço e do Tempo em Uma Vila em Remoção em Porto Alegre - RS. São ao todo trinta e sete fotografias, dispostas da seguinte maneira: dez no capítulo I, vinte e duas no Capítulo V e cinco no Capítulo VI. As fotografias coloridas foram fotocopiadas em tamanho $12 \times 8$, e inseridas no interior do texto. A autora discute o uso da fotografia na pesquisa, dizendo:

“(...), assim como foi por esta circulação conduzida pelas diferentes redes de vizinhança que aprendi a vivência interna da Cai-Cai como cruzamento de territorialidades, também foi pela observação do modo como estabeleciam elementos visuais, figuras referenciais para leitura $e$ orientação espacial na vila, e como interpretavam e valorizavam o uso da fotografia e suas linguagens visuais, que estabeleci o critério do uso da cor na seleção, enquadramento e composição da imagem fotográfica que utilizo nesta dissertação" (SANT’ANNA, 1997: 30).

Discutindo o aspecto cromático das fotografias em seu trabalho de campo, Maria Helena coloca que:

“(...) Em minhas primeiras sessões fotográficas, utilizei filmes preto e branco para a captação da imagem etnográfica. Retornando estas imagens para apreciação dos moradores, percebi, então, que as mesmas reforçavam uma imagem depreciativa e dominante a respeito da vila, não encaixando-se a uma auto-imagem positiva dos mesmos, nem à hierarquia de seus códigos visuais. Os comentários eram tecidos em duas ordens de consideração. A primeira, pela desvalorização da fotografia em preto e branco e primazia do uso da cor: "Ah! É fotografia preta e branca... Que pena! Por que não tira colorida?" A segunda, é de que as fotos devolviam-lhes uma imagem dominante da vila como "suja", "precária" e"miserável": "Olha aqui, 
deixa eu ver... Onde é isso aqui? É ali no dique? Bah! Mas é suja essa vila mesmo!" (Observação de morador, em conversa em uma roda na faixa). "Nossa, as maloquinhas... A gente olhando assim, né, que vê essa malocada toda, cheio de lixo em volta. Ó, o Messias correndo ali! Agora que eu vi...”(Margareth, mãe de Messias, olhando uma foto tirada da praia em direção às casas). A fotografia em preto e branco desorientava seus olhares, numa apresentação "chapada" de suas diversas texturas. A cor constituía-se em um elemento referencial importante de visualização e reconhecimento da morfologia e disposições sócio-espaciais da vila. Quantas vezes as pessoas davam indicações espaciais e territoriais complementadas pelo elemento da cor: "Tu entra naquele bequinho ali, onde tem aquela parede branca ali..." "Do bar azul prá cá, as mães cuidam dos filhos, do bar azul prá lá..."(Celuí, falando sobre como vivenciava suas diferenças com os vizinhos)".(SANT'ANNA, 1997: 30-31)

Esta citação nos revela sobre a importância da cor nas fotografias captadas em pesquisas, onde o antropólogo-fotógrafo procura devolver as imagens tomadas como uma forma de contra-presente e negociação de uma continuidade de relação com os sujeitos pesquisados. Pode-se sugerir, que nas pesquisas junto a grupos populares em Porto Alegre, os informantes em geral alertaram ao antropólogo-fotógrafo, o valor êmico atribuído as fotos coloridas que ilustravam seu cotidiano.

A autora numera as fotografias fazendo referência às mesmas em notas de rodapé. Não faz uso de moldura ou de índice das fotografias.

\section{Dissertações com exposições fotográficas}

Entre as últimas dissertações que fazem uso da imagem, tem sido freqüente a composição de uma exposição fotográfica organizada pelo NAVISUAL/UFRGS no dia da defesa pública e posteriormente pela Galeria Olho Nú (Multimeios/IFCH), pelo Museu Antropológico (SEC/RS), ou em eventos acadêmicos os mais diversos como Reunião da ABA Nacional, Reunião de Antropologia Mercosul, ANPOCS, etc. Nestas exposições, o tamanho das fotos varia de $18 \times 24$ a 30 × 40 .

Uma das primeiras dissertações a recorrer à montagem de uma exposição de fotografias no dia da defesa é a de Josiane A. Silva sobre a Escola de Samba Bambas da Orgia em Porto Alegre. A partir daí outros antropólogos selecionaram algumas entre as fotografias usadas no texto para organiza-las em exposições. Citamos a de Jurema Brites sobre o cotidiano de uma comunidade de religião afro-brasileira em Porto Alegre, a de Cláudia Turra Magni, sobre 
moradores de rua em Porto Alegre, a de Liliane S. Guterres, sobre a Escola Imperadores do Samba, a de Maria Helena Sant'Ana sobre os moradores da vila Cai-Cai em Porto Alegre, a de Édison Gastaldo sobre esportes de combate e a de Luiz Eduardo Achutti sobre a etnografia da reciclagem do lixo em vila periférica em Porto Alegre.

Citamos também a dissertação de Maria Clara Mocelin que não faz uso das fotografias no interior do texto mas realizou uma exposição de fotografias inaugurada no dia da defesa. Trata-se de um estudo sobre memória mítica entre descendentes de imigrantes da região colonial italiana. Auxiliada pelo bolsista do NAVISUAL na época, Nuno Godolphim, a autora captou imagens do universo, dos informantes e de detalhes do cotidiano.

Outros antropólogos organizaram a montagem de exposição do acervo fotográfico referente a etnografia construída em momentos posteriores, e divulgadas por ocasião de congressos e reuniões antropológicas. Como exemplo citamos a exposição de Adriane Rodolpho sobre práticas rituais dos sacrifícios de animais em casas de religião em Porto Alegre.

É relevante destacar que o formato de exposição permite um significativo retorno para a comunidade estudada, pela realização de exposições nos universos pesquisados, como em uma escola, por exemplo. Neste momento os informantes e demais membros do universo em questão podem apreciar as fotografias e comentá-las com o antropólogo.

O acervo fotográfico que compõem várias destas exposições como a de Boff, Guterres, Silva, Achutti, Gastaldo, Rodolpho e Godolphim, foram doadas para o NAVISUAL que desta forma pode sistematicamente expô-las por ocasião de eventos, congressos, jornadas e trabalhá-las na disciplina de Antropologia Visual e da Imagem. Atualmente várias destas imagens confeccionam a sessão “Tribos” no Museu da Dúvida da UFRGS.

Em alguns casos esta dinâmica do NAVISUAL precisa ser criteriosamente avaliada, pois nem sempre a exposição montada para uma circulação acadêmica restrita, pode contemplar uma divulgação pública mais ampla, dado os critérios éticos e resguardo das mesmas para o circuito científico.

Quando as fotos tem o aval da comunidade pesquisada para uma ampla divulgação, na mídia inclusive, sem dúvida a exposição adquire um formato que possibilita uma divulgação para um público diverso daquele restrito a academia.

\section{ANÁLISE DAS EXPERIÊNCIAS NO CAMPO VISUAL}

A força ilustrativa da fotografia é sempre um recurso válido na contextualização da pesquisa etnográfica, no sentido de permitir ao leitor conhecer imageticamente o cenário da 
pesquisa, os personagens entrevistados, as situações e eventos descritos, etc. A fotografia tem sido um instrumento eficaz para o antropólogo contextualizar visualmente sobretudo o universo não verbal do ambiente de pesquisa, para si e para o leitor. Digamos que esta seria uma primeira grande contribuição da fotografia no texto etnográfico. Fornece ao pesquisador um suporte visual — dado bruto - para sua elaboração teórica no momento de construção do texto etnográfico e, num segundo momento, sacia a imaginação curiosa do leitor, permitindo uma confrontação de sua suposição imaginária do contexto da pesquisa com o respectivo registro fotográfico apresentado.

Até aqui, o uso do recurso fotográfico proporciona ao leitor quase a mesma sensação e emoção de quem acaba de ler uma obra literária como "Os Sertões" de Euclides da Cunha, por exemplo, e tem acesso a um apêndice de fotos dos lugares, pessoas e acontecimentos narrados no livro. Sente-se prazer em enxergar o que foi descrito e imaginado, como matar a "fome de ver" depois de horas de leitura e imaginação. Pode-se também lembrar aqui o que é experimentado pela pessoa que contempla um álbum de fotografias de viagem. As fotos tornam o relato da viagem mais interessante, dão crédito - o tamanho do peixe na mão do pescador comprova a sua história. Se ele comprou o peixe para tirar a foto, aqui não importa: a foto também pode confirmar uma mentira significativa. As fotografias são vistas pelo leitor como documentos, testemunhas que comprovam que o viajante realmente esteve lá e viveu as situações narradas.

Aliás, esta capacidade de convencimento ao leitor de que o antropólogo esteve lá já foi comentada por Geertz ao tratar da descrição densa. Para este,

"esta capacidade de persuadir os leitores (...) de que o que eles estão lendo é o relato autêntico de alguém pessoalmente familiarizado com a vida em algum lugar, em determinado tempo, entre certo grupo, é a base em que repousa tudo o mais que a etnografia procura fazer - analisar, explicar, discutir, confundir, celebrar, edificar, desculpar, assombrar, subverter" (Geertz,1989:72).

Sugere-se aqui que o antropólogo que experimenta apreender o dado etnográfico através da fotografia, pesquisando situações, personagens, eventos, etc pode, não raro, proporcionar também uma experiência estética fascinante para o leitor. O que nos faz voltar a nossa motivação inicial em lembrar a queixa de Braudel com relação à ausência de fotografias no texto de Harris.

Esta perspectiva torna-se mais densa quando o mesmo leitor de Euclides da Cunha ou da viagem fotografada olha para as fotos de uma reportagem ou um fato jornalístico, como a famosa cena fotografada por Huynh Cong Tu (1972), que mostra crianças correndo e 
chorando por uma estrada do Vietnam fugindo do holocausto de sua aldeia bombardeada por napalm. ${ }^{9}$

Sugere-se aqui que a utilização da fotografia pelo antropólogo no processo de pesquisa e na elaboração do texto etnográfico vem se mostrando um instrumento eficaz na dinâmica de interação pesquisador/sujeitos e pesquisados/leitor corroborando na explicitação do processo de investigação que conecta o indivíduo e o acontecimento. Isto implica em dizer que avaliamos um aumento de qualidade das possibilidades de troca de informações, possibilitando aos leitores um maior acesso aos processos de produção de conhecimento do pesquisador.

A foto etnográfica tem o dever de ir além da curiosidade, do documento, da estética e da informação: deve esclarecer profundamente o que não pode ou não deve ser dito. Narrar com densidade aspectos de uma cultura que se fossem ditos perderiam toda a eloqüência. Tornar clara a câmara escura das manifestações visuais intraduzíveis, partilhar com o leitor um universo de descobertas sensíveis, subjetivas e pictoricamente significantes. Eduardo Viveiros de Castro assim se expressa com relação a esta contextualização, refletindo igualmente sobre a qualidade estética da percepção antropológica comunicada pelas imagens:

"Fiz estas fotografias para capturar aspectos da vida Yawalapíti que não podia traduzir em linguagem escrita e para comunicar o prazer propriamente estético despertado por minha percepção deles, meu prazer em olhá-los, difícil de ser incluído em um trabalho acadêmico. As monografias antropológicas deixam pouco espaço para os aspectos 'não-estruturais' da experiência perceptiva do investigador. Pelo contrário, deseja-se estruturar esta percepção: impressões difusas, prazer estético ou desespero existencial são normalmente comunicados aos amigos e colegas, ou transformados em 'literatura' na introdução às monografias. Prefiro realizar estas sensações de forma pública através das fotografias". (VIVEIROS DE CASTRO, 1996: 99)

Mas por que só agora, 50 anos depois da experiência de Margaret Mead e Gregory Bateson (1939), a presença da fotografia começa a conquistar um estatuto de legitimidade nas

\footnotetext{
9 Além de saciar a curiosidade sensacionalista do leitor, atestar a suposta veracidade do texto publicado e de proporcionar uma experiência estética, a foto jornalística busca a síntese do fato ocorrido. O leitor "mergulha" na imagem antes, durante e depois de ler o texto. De tal forma que a fotografia é sempre a melhor isca para apanhar o leitor que passa em frente a uma banca de jornais. Se a foto expressa o fato de forma eficiente, certamente desperta a curiosidade do leitor para ler sobre o acontecido. A foto no jornal é pensada, captada, editada e decodificada como uma informação que também deve ser lida. Neste sentido, a fotografia é tão ou mais importante que o texto que a acompanha. O espaço de comunicação fotográfica, hoje consolidado no jornalismo, foi negociado e construído historicamente em ressonância com a aquisição de uma cultura visual jornalística por parte do leitor. De certa forma, é o que está acontecendo hoje com a antropologia: a criação de um campo semântico visual próprio às suas especificidades ou demandas metodológicas.
} 
dissertações de mestrado e doutorado? É certo que a sua contribuição na etapa de levantamento de dados etnográficos já vem sendo largamente aceita pelos pesquisadores desde então, mas só recentemente começa a ser reconhecida a possibilidade da fotografia figurar também como "texto visual", ou seja, "afirmações e interpretações sobre o real" (ACHUTTI, 1996: 19). A fotografia deixa de ser vista como um mero adorno dispensável que, de certa forma, descaracterizaria a formalidade do texto científico, vulgarizando-o, e passa a desempenhar um papel discursivo, paralelo ao texto escrito, ampliando a superfície de contato entre o leitor e a experiência etnográfica.

Com isso, há uma mudança também na postura do leitor que olha para a fotografia no trabalho acadêmico.$^{10}$ Ele passa a procurar este texto nas fotos, ou melhor, se permite uma entrega a experiência visual. Assim como o espectador do cinema empresta a sua subjetividade por determinado tempo para dar sentido ao filme, o "foto-espectador" apreende as observações visuais do pesquisador, ampliando sua percepção sobre o objeto de análise em questão. Os detalhes dos personagens - os fenótipos, as rugas, vestimentas, adereços, utensílios, aparência — assim como os lugares ganham importância descritiva.

Nesse sentido, a disposição das fotos também comunica. A tensão entre a sucessão de uma foto e outra, dispostas em seqüência; o contraste de gestos, expressões faciais ou ambientes, lugares; a (des)continuidade espacial-temporal-emocional entre as imagens ou a própria passagem de tempo registrada em profundidade dentro de uma sucessão de fotos retratadas em uma única fotografia, permitem ao leitor compartilhar com o pesquisador as descobertas sensíveis (não verbais ou não verbalizáveis) da experiência etnográfica. Um bom exemplo disto é a sessão construída por Achutti denominada "Imagens dentro da Imagem" (ACHUTTI, 1996: 190-199). (Ver em anexo). Algumas dessas descobertas até poderiam ser verbalizadas, mas perderiam completamente sua força estética. (Ver em anexo ACHUTTI, 1996).

A importância do texto que acompanha a foto, jamais será negligenciável. Mas sugerimos que não menos válido é a opção de buscar pela foto ou pela montagem em sequiência expressar toda riqueza emocional e precisão descritiva que o pesquisador gostaria de comunicar.

Tendo por critério a montagem das fotos nos textos etnográficos inventariados, podemos observar que uma possibilidade recorrente é a de agrupar as fotos em anexo. Mas podemos também igualmente observar que desde as primeiras dissertações defendidas, os

10Neste sentido, Etienne Samain, a partir da análise de Crary sobre o "novo tipo de observador"que surge em inícios do séc. XIX, chama a atenção para a relação deste observador e a nova cultura visual contemporânea. (SAMAIN, 1996: 13) 
autores já fazem uso da inserção da fotografia no interior dos capítulos, seja no final destes, seja em página separada (ou mesmo um capítulo só de fotos), seja alternando-se com o texto. As opções de montagem dependem da intenção estilística do autor ao recorrer à fotografia na construção do texto etnográfico. Igualmente são variadas as opções dos autores com relação ao uso ou não de molduras (geralmente utilizadas quando as imagens são fotocópias reduzidas recortadas e coladas na folha) ou ainda com relação à legenda e/ou numeração das fotografias.

Um problema que salientamos anteriormente, quanto a reprodução em xerox $\mathrm{P} / \mathrm{B}$ de fotos coloridas, merece ser retomado com mais detalhes. $\mathrm{O}$ alto custo do processo de copiagem de imagens em cores tem motivado os pesquisadores que optaram pela obtenção de fotos coloridas durante a pesquisa a preferirem copiá-las através da tradicional fotocópia em preto e branco. As fotos originais, coloridas, ficam restritas às exposições e àquelas cópias da dissertação que são apresentadas aos professores. As cópias que ficam disponíveis ao grande público raramente são apresentadas conforme as originais. Desta forma, as possibilidades técnicas e estéticas oferecidas pelo uso da cor na fotografia, ressaltadas anteriormente por Maria Helena Sant'ana, sofrem uma perda qualitativa irreparável. Isto acontece por dois motivos básicos. O primeiro se refere à intenção estética do fotógrafo quando privilegia determinados elementos que deverão compor o enquadramento na hora da obtenção. Conforme analisamos anteriormente, muitas vezes a cor determina a própria escolha do motivo a ser fotografado. A mesma foto quando fotocopiada em preto e branco pode sofrer um profundo esvaziamento em sua verdadeira natureza estética. Em segundo lugar ocorre uma perda de fidelidade e alteração de contraste com a conversão cor/P\&B. Quando uma fotografia captada originalmente em preto e branco é fotocopiada também em $\mathrm{P} \& \mathrm{~B}$, o que se perde é a quantidade de tons de cinza presentes no original. A foto se torna mais contrastada e a perda é insignificante. Já o caso da cor é mais complicado. As fotos coloridas apresentam uma gradação de tons de cada cor do espectro para representar o nível de luz refletido pelas superfícies fotografadas. Assim, claros e escuros de cada objeto fotografado são apresentados em sua cor original: as áreas com maior incidência de luz correspondem aos tons de cor mais claros na foto e vice-versa. Toda essa infinita gradação tonal para a reprodução fiel das cores, luzes e sombras permitidas pelo processo químico da fotografia será substituída pelos dois únicos passíveis de serem reproduzidos pelo toner da máquina xerográfica: preto e branco. A perda de qualidade é incalculável, reduzindo um original em cores a um mero fragmento de imagem, por vezes indecifrável. 
Observamos ainda que a grande maioria dos pesquisadores opera diretamente a câmera fotográfica, desde as dissertações da década de 80. Em raras ocasiões o antropólogo solicita o auxílio profissional de um fotógrafo, sendo que algumas vezes, mais recentemente, vêm ocorrendo o trabalho conjunto do pesquisador em companhia de outro antropólogo-fotógrafo ou assessorados pelo NAVISUAL.

Este é o desafio destas produções: tentar trazer as fotografias como recurso interpretativo. É sobretudo das dissertações que recorrem à imagem integrada ao texto, ou a uma seqüência de imagens sobre um mesmo tema que avaliamos uma maior força narrativa. Neste sentido sugerimos uma narratividade visual, justamente pela riqueza com que, pela fotografia, pode-se descrever acontecimentos, formas interativas (indivíduo/ambiente, indivíduo/coletividade, etc.), processos sociais que levam o leitor a construção do conhecimento não só pela hegemonia da narrativa escrita.

A forma como estes autores recorrem à fotografia, ilustrando momentos de interação do pesquisador na experiência de campo, tem sido um recurso elucidador das estratégias de inserção no universo de pesquisa, das negociações de re-conhecimento e de troca no processo da experiência etnográfica. Não raro, o procedimento de captação e/ou devolução das imagens é motivação de profícuos diálogos e esclarecimento da visão dos entrevistados acerca do conteúdo das fotos, aspectos descritos em várias das dissertações citadas.

Neste experimento, podemos destacar as dissertações dos antropólogos Jacqueline Pólvora sobre Batuque, Cláudia T. Magni sobre nômades urbanos, Adriane Boff sobre namoro no rádio, a de Édison Gastaldo sobre kickboxers, Adriane Luisa Rodolpho sobre o sacrifício na Quimbanda, Liliane Guterres sobre Escola de Samba e Maria Helena Sant'Ana que problematiza a noção de espaço e pertencimento de moradores de uma vila em processo de remoção.

Tendo em comum o universo porto-alegrense, nestes textos etnográficos a fotografia surge como suporte para construções diferenciadas, ora expressando o olhar do antropólogo na busca de uma descrição densa, ora contextualizando a situação vivida no trabalho de campo ou, ainda, como uma narrativa que se costura ao texto escrito.

Assim, a crescente utilização da fotografia como recurso etnográfico pelos próprios antropólogos, tornados fotógrafos, traz à tona a necessidade de aprendizagem da "gramática visual" do instrumento. A partir do manejo adequado do equipamento e da técnica fotográfica, a fotografia etnográfica permite ao pesquisador manifestar visualmente aquilo que o texto verbal dificilmente conseguiria. As diferentes instâncias de intencionalidade presentes no ato fotográfico permitem ao pesquisador fotógrafo uma enunciação imagética extremamente 
precisa e de grande valia na construção da narratividade etnográfica.

Gostaríamos por último destacar as três últimas dissertações inventariadas no que diz respeito ao claro esforço de atribuir à fotografia um importante estatuto descritivo dando à imagem um lugar ainda inovador no processo de construção do texto. Para uma ciência onde a escrita permanece o veículo de comunicação legítima da pesquisa científica, é importante considerar a tentativa de garantir um espaço de experimentação e debate sobre as potencialidades da imagem na construção do saber etnográfico.

Trata-se dos trabalhos de Liliane Guterres, Luiz Eduardo Achutti e Maria Helena Sant'Ana que experienciam a busca de uma seqüência narrativa fotográfica, que teria como força estilística a narração de um acontecimento vivenciado. Neste caso, a imagem tem uma grande força contextualizadora e descritiva que revela o desenvolvimento visual da ação. (Ver em anexo os exemplos selecionados).

\section{Palavras finais}

No âmbito das atividades do NAVISUAL temos tido a oportunidade de dar continuidade ao exercício de reflexão proposto pelas dissertações de mestrado no desenvolvimento das oficinas "Bases Teóricas da Antropologia Visual", oficinas de formação em fotografia e vídeo, prolongando a análise efetuada nas dissertações. Através de discussões entre o grupo e os autores reflete-se sobre o próprio fazer antropológico: as questões surgidas e resolvidas no trabalho de campo, os encaminhamentos dados e posteriormente revistos, contribuem em muito para a qualidade da antropologia que se pretende.

Outro importante espaço da continuidade deste processo do lugar da Antropologia Visual é promovido nos diversos eventos científicos. Nestas situações, em âmbito nacional e mesmo internacional, têm-se discutido sobre o desenvolvimento recente do uso da linguagem imagética nas Ciências Sociais com o intuito de promover uma reflexão crítica mais profunda dos seus usos a partir da prática de ensino em Antropologia Visual. Neste sentido se destacam os encontros da ANPOCS, da Reunião Nacional de Antropologia, das Reuniões Regionais da ABA e do Mercosul, os festivais e mostras de filme etnográficos e outros eventos intrauniversitários. Essas formas experimentais do fazer etnográfico convergem com a discussão contemporânea sobre o "olhar para si"11 que a disciplina constrói.

\footnotetext{
${ }^{11}$ Segundo Clarice Peixoto e Patrícia Monte-Mór: "Na tentativa de repensar-se como disciplina, a antropologia aplica a si
} 
mesma sua prática de pesquisa: um olhar atento e uma descrição detalhada de uma dinâmica que, parece, deve ser reciclada". (1995: 7)

\section{REFERENCIAS}

ACHUTTI, Luiz Eduardo Robinson. Fotoetnografia: Um Estudo de Antropologia Visual Sobre Cotidiano, Lixo e Trabalho em Uma Vila Popular na Cidade de Porto Alegre. Dissertação de Mestrado. PPGAS/ UFRGS. 1996.

BITTENCOURT JÚNIOR, Iosvaldir. Relógios da Noite, uma Antropologia da Territorialidade e da Identidade Negra em Porto Alegre. Dissertação de Mestrado. PPGAS/ UFRGS. 1995.

BOFF, Adriane de Mello. O Namoro Está no Ar... Na Onda do Outro: Um Olhar Sobre os Afetos em Grupos Populares. Dissertação de Mestrado. PPGAS/ UFRGS. 1994

BRAUDEL, Fernand. Écrits sur l'histoire. Paris: Flammarion. 1969.

BRITES, Jurema Gorski. Aprendiz de Bacana: Mobilidade Social e Sociabilidade em uma Terreira Afro-Brasileira. Dissertação de Mestrado. PPGAS/ UFRGS. 1993.

BURKE, Peter. O mundo como teatro, estudos de antropologia histórica. Lisboa, Difel. 1996. CARDARELLO, Andrea Daniella Lamas. Implantando o Estatuto: Um Estudo Sobre a Criação de um Sistema Próximo ao Familiar para Crianças Institucionalizadas na FEBEM/RS. Dissertação de Mestrado. PPGAS/ UFRGS. 1996.

DIAS, Celso. Olê, Olá, Nosso Time Tá Botando Prá Quebrá: um estudo sobre torcidas organizadas de futebol no Brasil. Dissertação de Mestrado. PPGAS/ UFRGS. 1991.

ECKERT, Cornelia e GODOLPHIM, Nuno. (Org.) Revista Horizontes Antropológicos. Antropologia Visual. vol. II. Porto Alegre: Editora da Universidade Federal do Rio Grande do Sul. 1995.

ECKERT, Cornelia. Os Homens da Mina: Um Estudo das Condições de Vida e Representações dos Mineiros de Carvão em Charqueadas - RS. Dissertação de Mestrado. PPGAS/ UFRGS. 1985.

FERREIRA, Maria Letícia Mazzucchi. Folheando o Passado: Um Estudo Antropológico Sobre Memória e Identidade Social na Velhice.Dissertação de Mestrado. PPGAS/ UFRGS. 1995

GASTALDO, Édison. Kickboxers: Esportes de Combate e Identidade Masculina. Dissertação de Mestrado. PPGAS/ UFRGS. 1995

GEERTZ, Clifford. "Estar lá, escrever aqui". in Revista Diálogo n. 03 vol 22, 1989.

GODOLPHIM, Nuno. A fotografia como recurso narrativo: problemas sobre a apropriação da imagem enquanto mensagem antropológica. In: ECKERT, Cornelia e GODOLPHIM, Nuno. (Org.). Revista Horizontes Antropológicos. Antropologia Visual. vol. II. Porto Alegre: Editora da Universidade Federal do Rio Grande do Sul. 1995.

GUHRAN, Milton In ECKERT, Cornelia e GODOLPHIM, Nuno. (Org.) Revista Horizontes Antropológicos. Antropologia Visual. vol. II. Porto Alegre: Editora da Universidade Federal do Rio Grande do Sul. 1995.

GUTERRES, Liliane Stanisçuaski. "Sou Imperador até morrer”, um estudo sobre identidade, tempo e sociabilidade em uma Escola de Samba de Porto Alegre. Dissertação de Mestrado. PPGAS/ UFRGS. 1996.

LEAL, Ondina Fachel. A leitura social da novela das oito. Dissertação de Mestrado. PPGAS/ UFRGS. 1983.

MACIEL, Maria Eunice de Souza. Bailões, é disto que o povo gosta: Análise de uma prática cultural de classes populares no Rio Grande do Sul. Dissertação de Mestrado. PPGAS/ UFRGS. 1984

MAGNI, Cláudia Turra. Nomadismo Urbano: Uma Etnografia Sobre Moradores de Rua em Porto Alegre.Dissertação de Mestrado. PPGAS/ UFRGS. 1994

PEIXOTO, Clarice. MONTE-MÓR, Patrícia. Cadernos de Antropologia e Imagem. Universidade do Estado do Rio de Janeiro. Rio de Janeiro: UERJ. 1995. 
PÓLVORA, Jacqueline Britto. A Sagração do Cotidiano: Estudo de Sociabilidade de um Grupo de Batuqueiros - Porto Alegre/RS. Dissertação de Mestrado. PPGAS/ UFRGS. 1994

RIAL, Carmen Silvia. O Mar de Dentro: a transformação do Espaço Social na Lagoa da Conceição. Dissertação de Mestrado. PPGAS/ UFRGS. 1988.

RODOLPHO, Adriane Luisa. Entre a Hóstia e o Almoço: Um Estudo Sobre o Sacrifício na Quimbanda. Dissertação de Mestrado. PPGAS/ UFRGS. 1994.

SALVATORI, Elena. Nem Tudo Que Reluz É Ouro. Estilo de Vida e Sociabilidade na Construção de um Espaço Urbano de Prestígio em Porto Alegre/RS. Dissertação de Mestrado. PPGAS/ UFRGS. 1996.

SAMAIN, Etienne. "Questões heurísticas em torno do uso das imagens nas Ciências Sociais. Palestra proferida para o Programa de Pós-Graduação em Antropologia Social em 1996. Porto Alegre, IFCH, UFRGS, 1996.

SAMAIN, Etienne. "Ver" e "dizer" na tradição etnográfica: Bronislaw Malinowski e a fotografia. In: ECKERT, Cornelia e GODOLPHIM, Nuno. (Org.). Revista Horizontes Antropológicos. Antropologia Visual. vol. II. Porto Alegre: Editora da Universidade Federal do Rio Grande do Sul. 1995.

SANT'ANNA, Maria Helena. Vila Cai-Cai: A Lógica da Habitação Reciclável. Estudo da Organização do Espaço e do Tempo em Uma Vila em Remoção em Porto Alegre - RS. Dissertação de Mestrado. PPGAS/ UFRGS. 1997.

SANTOS, João Aníbal dos. Televisão: Cultura Local e Cultura de Massa Global. Etnografia da Audiência Entre Descendentes de Imigrantes Alemães Dissertação de Mestrado. PPGAS/ UFRGS. 1995.

SILVA, Josiane A. Bambas da Orgia, um estudo sobre o carnaval de rua de Porto Alegre, seus carnavalescos e os territórios negros de Dissertação de Mestrado. PPGAS/ UFRGS. 1993.

VIVEIROS DE CASTRO, Eduardo. "Dois Rituais do Xingu". In PEIXOTO, Clarice. MONTE-MÓR, Patrícia. Cadernos de Antropologia e Imagem. Universidade do Estado do Rio de Janeiro. Rio de Janeiro: UERJ. 1996. 